\title{
Highly conductive nanoclustered carbon:nickel films grown by pulsed laser deposition
}

\author{
K. D. G. I. Jayawardena, Y. Y. Tan, J. Fryar, H. Shiozawa, S. R. P. Silva, S. J. Henley* \\ Nanoelectronics Centre, Advanced Technology Institute, University of Surrey, Guildford, Surrey, \\ GU2 $7 X H, U K$.
}

\author{
G. M. Fuge, B. S. Truscott, M. N. R. Ashfold \\ School of Chemistry, University of Bristol, Cantock's Close, Bristol BS8 1TS, UK
}

\begin{abstract}
An enhancement by 5 orders of magnitude of the electrical conductivity of nanoclustered carbon films is reported by incorporation of metallic atoms, but without significant morphological changes. Films were deposited by $248 \mathrm{~nm}$ pulsed laser ablation of both a pyrolytic graphite target and a mixed carbon-nickel (C:Ni) target, and structural analysis revealed that similar film morphologies were obtained when deposition was carried out using either target. Compositional analysis demonstrated a preferential incorporation of nickel over carbon in the resulting films (cf. the composition of the target). This non-stoichiometric transfer was also observed for films grown by $193 \mathrm{~nm}$ laser ablation of the C:Ni target, for which the enhancement was more pronounced, indicating that the ablation mechanism and the subsequent transfer are important in determining the eventual film composition.
\end{abstract}

*Corresponding author. Fax: +44 148368 6081. E-mail address: s.henley@ surrey.ac.uk 


\section{Introduction}

Nanostructured carbon is attracting increasing interest among the research community due to its potential applicability in areas as diverse as electrochemistry, gas sensing, catalysis, energy storage, and photovoltaics[1-2]. While the usefulness of carbon in many of these applications critically depends on its ability to form both $s p^{2}$ and $s p^{3}$ bonds, the morphology of the material also has an important effect on its overall properties[3].

Some of the more recently discovered nanostructures of carbon, i.e. those formed through cluster assembly[4-5], exhibit particular physical properties, e.g. high porosity and large surface area ( $300-800 \mathrm{~m}^{2} \mathrm{~g}^{-1}$ )[6-7], which could make them ideal candidates for chemical sensing applications. However, $s p^{3}$ bond formation at the surface of the clusters renders them poor electrical conductors[8], making electrical detection of species very challenging. If the electrical conductivity of these cluster-assembled films could be enhanced, it would most likely increase their utility in engineering applications.

One possible route toward increasing their conductivity (and thus improving their sensing properties) is through alloying with metallic elements such as Mo, Co or Ni[1, 9]. Preparation of carbon structures in which metallic elements are included during synthesis have been studied for many years[10-12], but there are few reports on the effect of incorporated metallic elements on the electrical properties of nanoclustered carbon films[7, 9].

Most previous reports employed supersonic cluster beam techniques to grow films of nanoclustered carbon doped with metallic elements. Pulsed laser deposition (PLD) is another technique that may be used to produce multi-element thin films[13-15]; here, multi-component nanostructures may be formed by simultaneous ablation of multiple targets and/or ablation of a composite target. Despite assertions that ablation of a composite target results in stoichiometric deposition[16], there have also been reported cases of non-stoichiometric thin film deposition[15, 17].

Recently, we reported the preparation of nanostructured carbon thin films of differing morphologies by PLD, with morphological control achieved simply by varying the background gas pressure during laser ablation of a pyrolytic graphite target[18-19]. Here we report the electrical properties of such nanoclustered films and demonstrate how their conduction properties can be enhanced due to metal incorporation, presently achieved through PLA of a C:Ni composite target.

\section{Experiment}

Films were deposited by pulsed laser ablation (PLA) of either a pyrolytic graphite target (purity of 99.999\%, Kurt J. Lesker) or a pressed carbon-nickel target containing 20 at. \% Ni (purity of 99.9\%, PI-KEM Ltd.). A Lambda Physik LPX 210i excimer laser was used, operating at ( = 248 $\mathrm{nm}$ (pulse duration: $25 \mathrm{~ns}$, repetition rate: $10 \mathrm{~Hz}$, incident fluence on target $F=6 \mathrm{~J} \mathrm{~cm}^{-2}$ ). Growth was carried out inside a chamber that was evacuated to a base pressure $p$ ? $10^{-6}$ Torr and backfilled with argon. Deposition was carried under various Ar pressures in the range 5 ( $p$ ( 340 mTorr. 
All of the deposited films were analysed both as-grown, and after annealing in a tube furnace at $573 \mathrm{~K}$ for 30 minutes under a $\mathrm{He}$ atmosphere. Film morphologies were characterized using a Philips XL30 and FEI Quanta 200F scanning electron microscopes (SEMs). Raman spectroscopy (Renishaw Micro Raman 2000, excitation wavelength of $514.5 \mathrm{~nm}$ ) was used for structural characterization. The carbon/nickel ratio was determined (as atomic weight percentages) from films deposited on a 2" silicon wafer with the aid of an Oxford INCA Penta FETx3 EDX system. To explore the effect of ablation wavelength on film composition, films deposited using similar $F$ but at ( = 193 nm (Lambda Physik COMPex 201 laser operating with ArF; pulse duration: ? 20 ns; repetition rate: $10 \mathrm{~Hz}$ ) were also subjected to EDX analysis.

Electrical measurements were performed using the two-probe technique on a Keithley 4200 semiconductor characterization system. The bottom contacts for these electrical measurements were formed using $\mathrm{Cr}$ pads of $100 \mathrm{~nm}$ thickness and 100 ?m spacing, patterned using photolithography.

\section{Results and Discussion}

\subsection{Structure and Morphology}

SEM images indicating the surface morphology of thin films deposited by $248 \mathrm{~nm}$ PLA of the mixed C:Ni target in different $p(\mathrm{Ar})$ are given in Fig. 1, panels (a) - (d). The undoped nanostructures prepared using the pyrolytic graphite target display similar morphologies to those reported previously in [18] and [19]. Except for the presence of a low density of $\mathrm{Ni}$ nanodroplets, the as-deposited thin films formed from either target at any given $p(\mathrm{Ar})$ show few obvious differences. As Figure 1 shows, and as discussed previously[18-19], the deposited film varies from a scratch-resistant diamond-like coating at low $p(\mathrm{Ar})$ to self-assembled clusters at higher pressures. This cluster assembly has been attributed to the presence of Ar, which presents a higher collision cross-section than lighter background gases such as He[18]. Figure 1 panels (e) - (f) display the microstructure of the film prepared by PLA of the mixed C:Ni target at $248 \mathrm{~nm}$, in $p($ Ar $)=340$ mTorr, before and after annealing, respectively. 


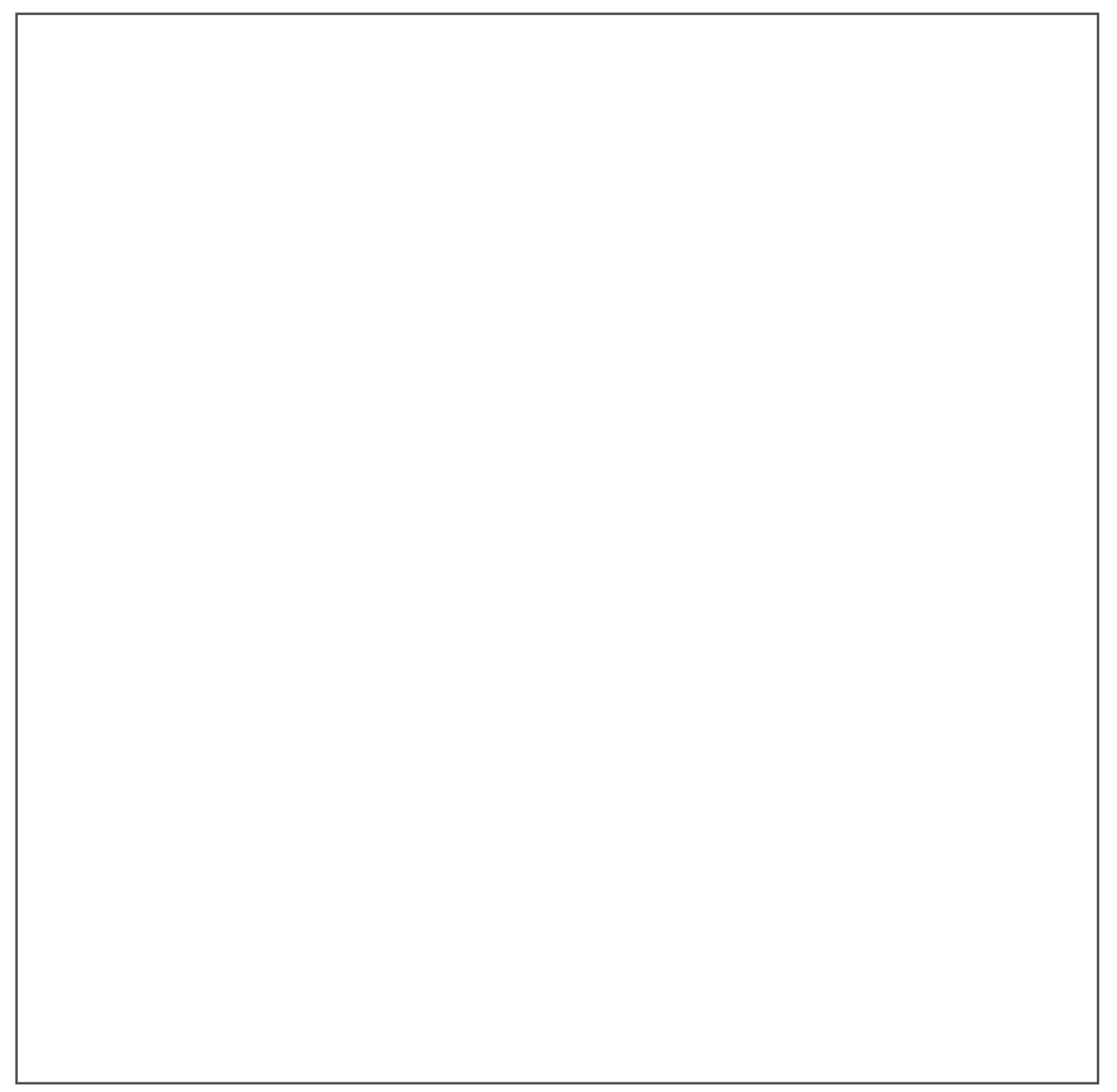

Fig. 1. Plan view SEM micrographs of thin films formed by $248 \mathrm{~nm}$ PLA of the C:Ni target at $p(\mathrm{Ar})=$ (a) 5 mTorr, (b) 40 mTorr, (c) 100 mTorr and (d) 340 mTorr. The inset in panel (d), where the scale bar is $2 ? \mathrm{~m}$, shows the foam-like structure of the film deposited at the edge of the substrate under $p(\mathrm{Ar})=340$ mTorr. Panels (e) and (f) are expanded micrographs of films deposited at $p(\mathrm{Ar})=$ at $340 \mathrm{mTorr}$, before and after annealing at $573 \mathrm{~K}$ respectively. No clear structural change is evident upon annealing.

Despite the broad similarity of the SEM images of the films taken before and after annealing, previous studies of pure [20] and Ni-doped [1] carbon thin films have hinted at the possibility of a change of microstructure, which we consider deserving of further attention. Furthermore, Raman spectroscopy is likely to provide a stronger diagnostic of such structural changes than is electron microscopy[21]. Thus, Figure 2 shows Raman spectra of thin films grown by $248 \mathrm{~nm}$ PLA of the pyrolytic graphite and mixed C:Ni targets, both before and after annealing. The Raman spectra of 
amorphous carbons consists of $\mathrm{D}$ and $\mathrm{G}$ peaks which are due to the breathing mode of $s p^{2}$ rings (D peak) and bond stretching in $s p^{2}$ rings and chains (G peak)[22]. Figure 3 shows the $I(\mathrm{D}) / I(\mathrm{G})$ ratio (calculated from each spectrum using peak heights determined by fitting the $\mathrm{D}$ peak to a Lorentzian and the G peak to a Breit-Wigner-Fano line shape [21]) along with the respective $G$ peak wavenumbers.

Fig. 2. $514.5 \mathrm{~nm}$ Raman spectra of the (a) as-deposited and (b) annealed films grown at several different values of $p(\mathrm{Ar})$ by $248 \mathrm{~nm}$ PLA of the pyrolytic graphite target; (c) and (d) are corresponding spectra of the as-deposited and annealed films, respectively, that were grown from the mixed C:Ni target, again by $248 \mathrm{~nm}$ PLA at various $p(\mathrm{Ar})$. The values of $p(\mathrm{Ar})$ under which these films were produced were (i) 5, (ii) 40, (iii) 100 and (iv) 340 mTorr. 


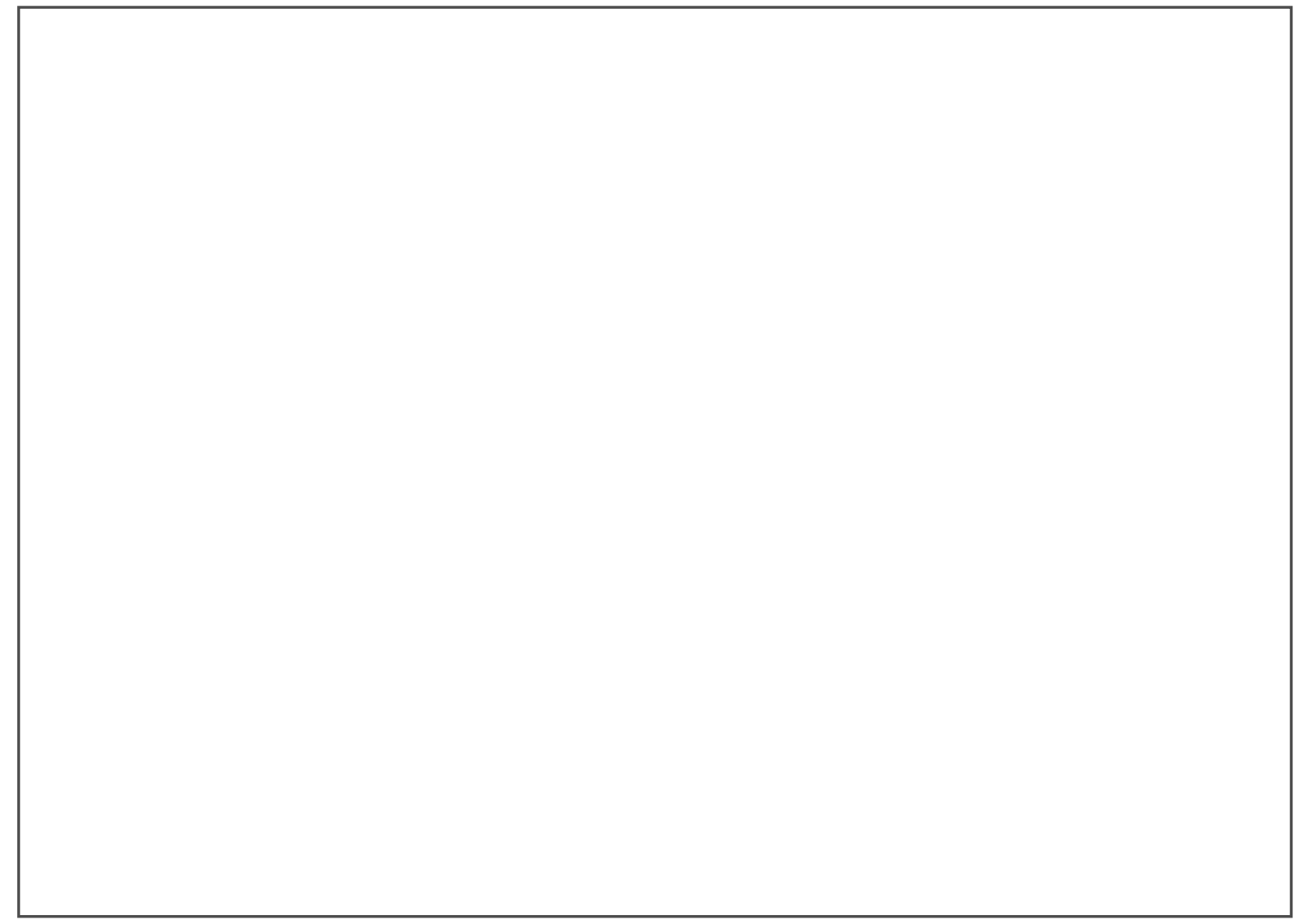

Fig. 3. $I(\mathrm{D}) / I(\mathrm{G})$ ratios from the Raman spectra of the as-deposited (filled symbols) and annealed (open symbols) films grown at different $p$ (Ar) by $248 \mathrm{~nm}$ PLA of (a) the pyrolytic graphite target and (b) the mixed C:Ni target. The G-peak wavenumbers are indicated in panel (c) for the films deposited using the pyrolytic graphite target and in panel (d) for the $\mathrm{C}$ :Ni target. The dashed lines are intended to reflect the approximate trend with pressure for the as-deposited and annealed films, respectively.

The observed variation of the $I(\mathrm{D}) / I(\mathrm{G})$ ratio for the undoped thin films, as presented in Fig. 3 (a), reproduces that reported previously[19]. The G-peak positions of the as-deposited undoped thin films grown at $p(\mathrm{Ar})>5$ mTorr are seen to fall consistently in the range $1550-1580 \mathrm{~cm}^{-1}$. Comparing the above data with the amorphization trajectory proposed by Ferrari and Robertson[21] suggests that undoped films formed under higher $p(\mathrm{Ar})$ have a higher $s p^{2}$ cluster content than those grown at $p(\mathrm{Ar})=5 \mathrm{mTorr}$, for which the G-peak lies further to the blue at ? $1540 \mathrm{~cm}^{-1}$. Upon annealing, the $I(\mathrm{D}) / I(\mathrm{G})$ ratios for the films grown at 40 ( $p(\mathrm{Ar})(340 \mathrm{mTorr}$ are almost unchanged, and the G-peak positions are shifted (to the red) by only ? $20 \mathrm{~cm}^{-1}$. The effect of annealing the film grown at $p(\mathrm{Ar})=5$ mTorr is more dramatic: the $I(\mathrm{D}) / I(\mathrm{G})$ ratio increases markedly, and the $G$ peak frequency increases by ? $40 \mathrm{~cm}^{-1}$. Both observations suggest that the principal consequence of annealing is an improved ordering of the $s p^{2}$ content for the $p(\mathrm{Ar})=5 \mathrm{mTorr}$ film[21, 23]. While it might be tempting to ascribe the increase in $I(\mathrm{D}) / I(\mathrm{G})$ ratio and shift of the $\mathrm{G}$ peak position to some corresponding reduction in $s p^{3}$ content - as proposed by Sullivan et al.[20] — we note that such an implied $s p^{3}$ ( $s p^{2}$ conversion is considered impossible in undoped films at such a low annealing temperature as was employed in the present 
work[24].

The $I(\mathrm{D}) / I(\mathrm{G})$ ratios in the Raman spectra of the as-deposited films grown from the mixed $\mathrm{C}: \mathrm{Ni}$ target show an increasing trend with $p(\mathrm{Ar})$, whereas, in contrast, this ratio decreases with increasing $p(\mathrm{Ar})$ for the as-deposited films obtained from the pyrolytic graphite target. Notably, the $I(\mathrm{D}) / I(\mathrm{G})$ ratios for the films grown using the mixed C:Ni target decrease markedly between $p(\mathrm{Ar})=5$ and 40 mTorr, but thereafter increase — implying the formation of relatively more graphitic nanostructures at higher $p(\mathrm{Ar})$. Annealing of the as-deposited films leads to an increase in the $I(\mathrm{D}) / I(\mathrm{G})$ ratio, consistent with enhanced $s p^{2}$ cluster formation.

The $\mathrm{G}$ peak positions[21] for films grown from the mixed C:Ni target, i.e. ? $1540-1555 \mathrm{~cm}^{-1}$, indicate the formation of an amorphous carbon nanostructure, despite the presence of a catalytic agent $(\mathrm{Ni})$ in the hot plasma plume. The increases in $I(\mathrm{D}) / I(\mathrm{G})$ ratio and $\mathrm{G}$ peak position upon annealing, however, leads to the conclusion that these evolve into graphitic structures. A comparison of the trends observed for both types of film would suggest that ablation of a mixed target containing a catalytic element in this range of $p(\mathrm{Ar})$ is not a viable route to forming graphitic nanostructures at room temperature. The only significant difference is in the case of films deposited at $p(\mathrm{Ar})=5 \mathrm{mTorr}$, where the presence of $\mathrm{Ni}$ results in relatively higher $s p^{2}$ cluster content in the composite versus the undoped film.

\subsection{Electrical Properties}

The $I-V$ characteristics of the as-grown and annealed thin films formed by $248 \mathrm{~nm}$ PLA of the pyrolytic graphite and the mixed C:Ni targets under four different $p(\mathrm{Ar})$ are presented in Figure 4. All samples display $I-V$ properties that are symmetric about $V=0$, indicating a non-contact related (i.e. bulk related) transport mechanism[25-26], irrespective of the inclusion of nickel. Except for those deposited at $p(\mathrm{Ar})=5 \mathrm{mTorr}$, all of the samples display an almost linear $I$ $V$ behaviour upon deposition. One important feature to be observed in the $I-V$ characteristics is the appearance of a hysteresis in the as-deposited cluster assembled nanostructures (both doped and undoped where the current during the reverse sweep is observed to be greater than the forward sweep. While molecular due to gas species might be a possible cause of this slight increase in conductivity, it is more likely that the enhancement observed is due to a conditioning effect leading to a better packed structure as a result of the charge transport through the clusters. The absences of hysteresis on both the doped and undoped cluster assembled films appear to support this conclusion. 


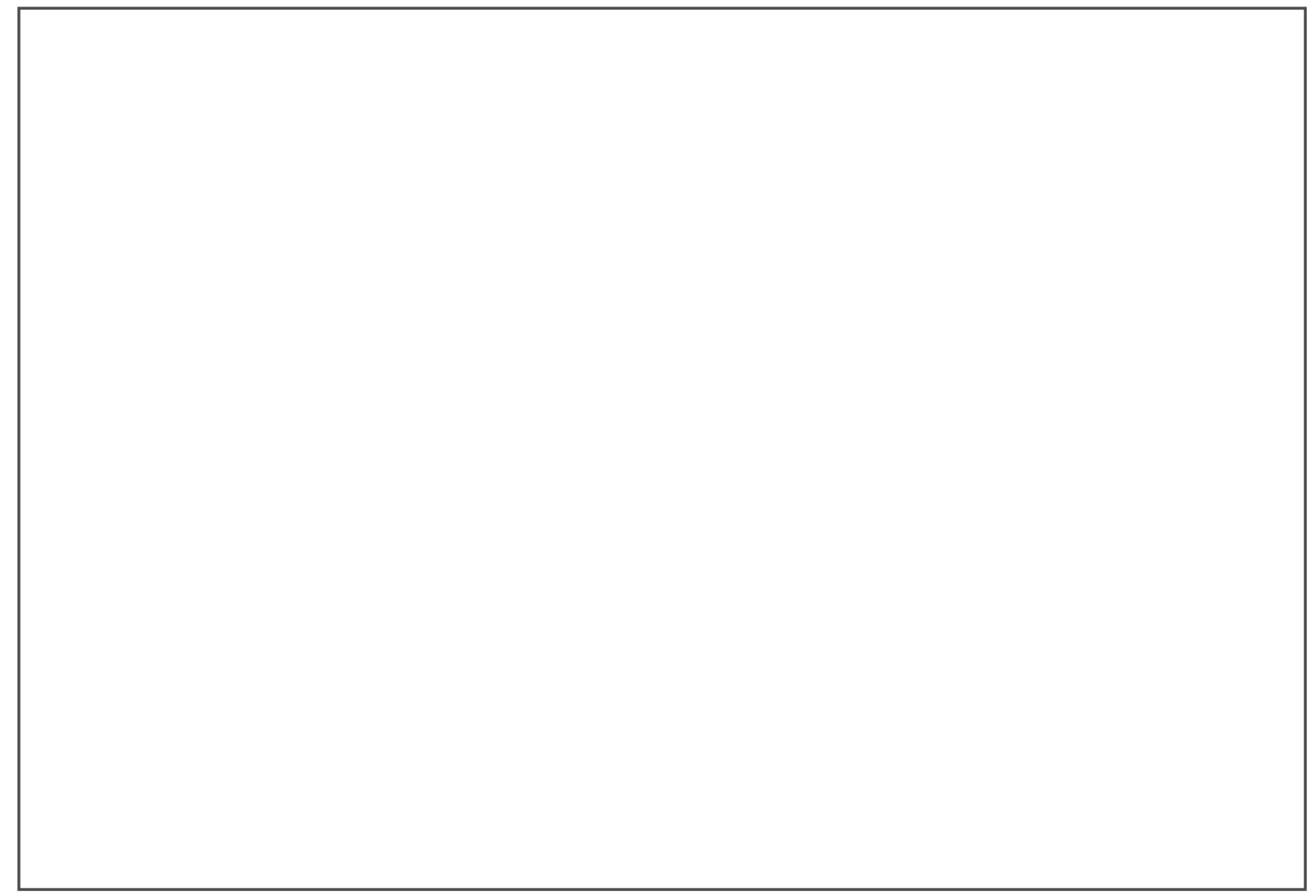

Fig. 4. $I-V$ characteristics of films grown by $248 \mathrm{~nm}$ PLA of the pyrolytic graphite and the mixed C:Ni target at $p(\mathrm{Ar})=$ (a) 5, (b) 40, (c) 100 and (d) 340 mTorr. The label C indicates curves for films deposited using the pyrolytic graphite target, while curves labelled with $\mathrm{C}: \mathrm{Ni}$ are those for the films deposited using the mixed target.

Various charge transport mechanisms have been proposed for amorphous carbon thin films, but a hopping mechanism wherein the conductivity is proportional to the overlap of the wavefunctions associated with adjacent hopping sites is generally considered the most probable explanation in the case of cluster-assembled films such as those reported here[7-8]. As discussed above on the basis of the evidence from Raman spectroscopy, annealing of the pure carbon thin films does not induce such a significant increase in $s p^{2}$ cluster content as might affect the transport properties. Ferrari et al.[24] suggest that annealing at temperatures below ? 873-973 K produces only a small number of new $s p^{2}$ sites, inside an $s p^{3}$ phase, but that these additional sites may cause an exponential increase in conductivity due to the (slight) increase in hopping centres. Since clusterassembled carbon films contain similar structures[6], it is likely that a similar mechanism leads to the enhanced conductivity observed here upon annealing of the undoped films.

The $I-V$ curves measured for the films prepared by $248 \mathrm{~nm}$ PLA of the mixed C:Ni target, display the following characteristics:

i. $p(\mathrm{Ar})=5$ mTorr: The measured current in the case of the as-deposited film with included $\mathrm{Ni}$ is ? $10^{3}$ times larger than for the pure carbon film. Annealing of the Ni-containing film had little effect on its $I-V$ characteristics, whereas annealing the pure carbon film deposited 
at this $p($ Ar) led to a substantial increase in its conductivity.

ii. $p(\mathrm{Ar})=40$ mTorr: Inclusion of Ni causes an approximately ten-fold enhancement in the conductivity of the as-deposited material (as compared to a film grown by PLA of the pyrolytic graphite target). This enhancement is much less than in the case of films grown at $p(\mathrm{Ar})=5$ mTorr, most likely due to the cluster-like nature of the film grown at higher $p$ (Ar). Upon annealing, a similar conductivity enhancement in favour of the $\mathrm{C}: \mathrm{Ni}$ film is maintained.

iii. $p(\mathrm{Ar})=100$ mTorr: The as-deposited films are poor conductors; poorer even than the pure carbon coatings formed by PLA of the pyrolytic graphite target at this $p(\mathrm{Ar})$. Annealing causes a dramatic $\left(? 10^{5} \times\right)$ increase in conductivity (cf. ? $10^{2} \times$ for the undoped films), presumably due to the resulting graphitization[1].

iv. $p(\mathrm{Ar})=340$ mTorr: Both the $I-V$ characteristics of the as-grown films and the (very evident) conductivity enhancement upon annealing are similar to those for the films deposited at $p(\mathrm{Ar})=100$ mTorr.

As discussed previously, inspection of SEM micrographs (Fig. 1) suggests no significant morphological or structural change upon annealing of the Ni-doped sample. Further measurements will be required to ensure that annealing causes no significant change in, for example, porosity. Nonetheless, the cluster-like nature of these annealed films combined with their enhanced conductivity suggests that they may be promising candidate materials for gas sensing applications.

\subsection{Elemental composition of the C:Ni films}

One factor that needs to be taken into consideration in explaining the electrical properties of these films is the percentage inclusion of nickel. PLA of mixed targets comprising of elements with very different atomic weights can lead to non-stoichiometric film deposition, as has been shown in the case of $\mathrm{LaAlO}_{3}[17]$. A better understanding of the electrical properties of the present thin films thus requires an assessment of their $\mathrm{Ni}$ content, especially considering that the ablation plume dynamics are likely to be further influenced by the presence of a background gas.

EDX analysis indicates that non-stoichiometric transfer has indeed occurred in the present case: the $\mathrm{Ni}$ content of the films deposited using the $\mathrm{C}: \mathrm{Ni}$ target is higher than that of the target. Approximate values for atomic percentages of $\mathrm{C}$ and $\mathrm{Ni}$ as calculated from measured $\mathrm{EDX}$ spectra without any $Z A F$ (here $Z, A$ and $F$ stands for -correction due to atomic number, absorption and fluorescence) corrections are given in Table 1.

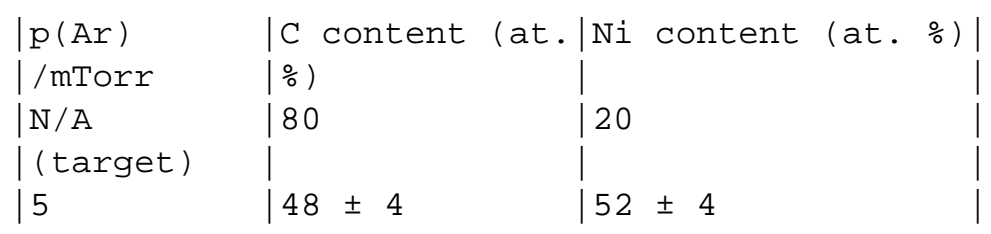


$\mid$\begin{tabular}{l|l|l}
40 & $\mid 57 \pm 1$ & $43 \pm 1$ \\
100 & $\mid 61 \pm 2$ & $\mid 39 \pm 2$ \\
340 & $\mid 54 \pm 2$ & $46 \pm 2$
\end{tabular}

Table 1. C and Ni content (in at. \%) as determined by EDX spectroscopy for the target and for films deposited by PLA of the mixed C:Ni target at different $p(\mathrm{Ar})$.

Spatially resolved EDX measurements across a large-area deposition (Fig. 5) show that the Ni content, and hence the non-stoichiometric nature, of the films is position-dependent. Specifically, we find that the enhancement of Ni transfer efficiency is most pronounced at the centre of the film, i.e. along the target surface normal.

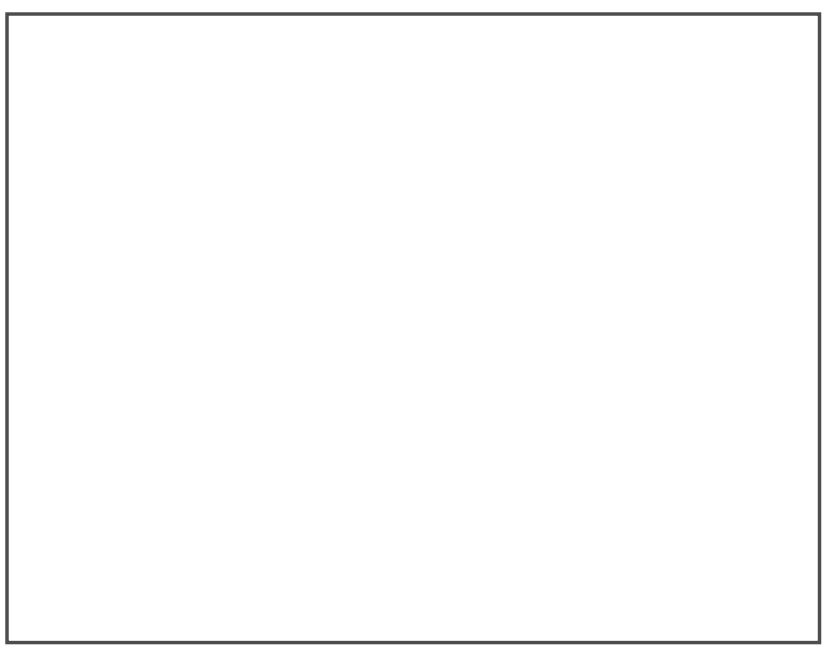

Fig. 5. Spatial variation of the nickel content (in at. \%) for the film deposited by $248 \mathrm{~nm}$ PLA of the $\mathrm{C}: \mathrm{Ni}$ target in $p(\mathrm{Ar})=340 \mathrm{mTorr}$.

Additional experimental evidence for the above conclusions was sought through an XPS analysis of the film grown at $p(\mathrm{Ar})=340$ mTorr. This returned $\mathrm{C}$ and $\mathrm{Ni}$ atomic percentages of $53 \%$ and $47 \%$, respectively, which coincide with those obtained by EDX (cf. Table 1), and thus reinforce the finding that material transfer from the target to the substrate is strongly non-stoichiometric and results in significantly enhanced $\mathrm{Ni}$ content of the deposited films.

To explore the effect of laser wavelength on non-stoichiometric transfer during PLA, the compositions of films deposited at different $p(\mathrm{Ar})$ by $193 \mathrm{~nm}$ ablation of the same mixed $\mathrm{C}: \mathrm{Ni}$ target were analysed by EDX spectroscopy. As Fig. 6 shows, these films exhibit very different morphologies to those obtained by $248 \mathrm{~nm}$ PLA, with little evidence of cluster formation even at the higher deposition pressures. Furthermore, a simple scratch-resistance test suggests that the material deposited by $193 \mathrm{~nm}$ PLA is significantly harder than that formed by $248 \mathrm{~nm}$ PLA at all $p$ (Ar), suggesting that the former films are more $s p^{3}$-like in structure. Although argon was used as the background gas during film deposition at both ablation wavelengths, the gas flow within the chamber differed between the two experiments and so the non-observation of discrete clusters in the resulting films may reflect a consequent difference in cluster diffusion dynamics[18]. Alternatively, or in addition, if it were found that $193 \mathrm{~nm}$ PLA produces more energetic material, 
then this might account for the difference in observed morphologies and could also explain the fractured appearance, as presented in Fig. $6(\mathrm{~d})$, of the film obtained at $p(\mathrm{Ar})=340 \mathrm{mTorr}$.

EDX analysis of films deposited following $193 \mathrm{~nm}$ PLA of the C:Ni target reveals nonstoichiometric transfer at all experimental values of $p(\mathrm{Ar}$ ), as shown by the $\mathrm{C}: \mathrm{Ni}$ ratios (at. \%) inset in the various panels of Fig. 6. These $\mathrm{C}: \mathrm{Ni}$ ratios are consistently smaller than those determined in the same way for films grown by $248 \mathrm{~nm}$ PLA of the same target at the same $p(\mathrm{Ar})$. The C:Ni ratio in the film grown in vacuum, i.e. $p(\mathrm{Ar})$ ? 0 , implies that material transfer in the case of deposition from an unconstrained PLA plume is approximately stoichiometric, while increasing $p(\mathrm{Ar})$ clearly results in a bias that is progressively more in favour of $\mathrm{Ni}$ transfer and incorporation. Investigations of the PLA plume dynamics and further spectroscopic experiments are currently underway, from which we hope to obtain a better understanding of this nonstoichiometric transfer.

Fig. 6. SEM images of thin films deposited following $193 \mathrm{~nm}$ PLA of the C:Ni target at $p(\mathrm{Ar})=$ (a) $10^{-3}$ mTorr, (b) 40 mTorr, (c) 100 mTorr and (d) 340 mTorr. The C:Ni ratios inset in each image indicate the atomic percentage of the two elements as obtained through EDX analysis.

The relatively high $\mathrm{Ni}$ fractions in films grown by $248 \mathrm{~nm}$ PLA of the $\mathrm{C}: \mathrm{Ni}$ target may provoke the expectation that their conductivity should be enhanced relative to that of their pure carbon counterparts under all deposition conditions. However, it is conceivable that, depending on 
process parameters, the $\mathrm{Ni}$ atoms may be incorporated in such a way as to be either encapsulated by carbon, or exposed to the environment. In the former scenario, $\mathrm{Ni}$ would be protected from oxidation (by the surrounding carbon layer), while in the latter, $\mathrm{NiO}$ (a weak conductor) would likely be formed in place of elemental $\mathrm{Ni}$. The effect of such oxidation would likely be more pronounced in cluster-assembled films due to their high surface area, thereby offering a plausible explanation for the poorer conductivity of the as-deposited cluster assembled material.

\section{Summary}

A broad similarity has been demonstrated between the structural properties of as-deposited thin films prepared by $248 \mathrm{~nm}$ PLA of a pyrolytic graphite and a mixed C:Ni target in various background pressures of Ar. The undoped thin films appear to undergo little morphological change on annealing, whereas the same treatment applied to the films grown from the $\mathrm{C}: \mathrm{Ni}$ target appears to result in increased $s p^{2}$ cluster formation. Despite different structural trends observed in the films of each composition pre- and post-annealing, both types of film demonstrate enhanced conductivity as a result of this processing. In the former case, this can be attributed to some increase in $s p^{2}$ content upon annealing, albeit not one so pronounced as to provoke significant morphological changes. The enhanced conductivity of the C:Ni films relative to those formed by PLA of pyrolytic graphite reflects a non-stoichiometric transfer of material by PLD, which leads to a greater proportion of $\mathrm{Ni}$ in the film as compared to the target. Our demonstration that the conductivity of nanostructured carbon can be enhanced significantly by co-deposition of $\mathrm{Ni}$ from a mixed C:Ni target, and further when combined with a relatively low-temperature annealing process that preserves the morphology, is encouraging toward the use of these high surface area carbon nanocluster/metal alloy thin films in gas sensing applications.

\section{Acknowledgement}

The authors thank the EPSRC (UK) for funding this work and the studentships awarded. Grant numbers: EP/FO52901/1 (Surrey), EP/FO48068/1 (Bristol).

\section{References}

1. Agostino RG, Caruso T, Chiarello G, Cupolillo A, Pacilé D, Filosa R, et al. Thermal annealing and hydrogen exposure effects on cluster-assembled nanostructured carbon films embedded with transition metal nanoparticles. Phys. Rev. B, 2003; 68: 035413.

2. Nismy NA, Adikaari AADT, Silva SRP. Functionalized multiwall carbon nanotubes incorporated polymer/fullerene hybrid photovoltaics. Appl. Phys. Lett., 2010; 97(3): 033205.

3. Rode AV, Gamaly EG, Christy AG, Fitz-Gerald JG, Hyde ST, Elliman RG, et al. Unconventional magnetism in all-carbon nanofoam. Phys. Rev. B, 2004; 70(5): 054407.

4. Rode AV, Gamaly EG, Luther-Davies B. Formation of cluster-assembled carbon nanofoam by high-repetition-rate laser ablation. Appl. Phys. A, Mater. Sci. and Proc, 2000; 70(2): 135-144.

5. Milani P, Podesta A, Piseri P, Barborini E, Lenardi C, Castelnovo C. Cluster assembling of nanostructured carbon films. Diam. Relat. Mater., 2001; 10(2): 240-247.

6. Rode AV, Hyde ST, Gamaly EG, Elliman RG, Mckenzie DR, Bulcock S. Structural analysis of a carbon foam formed by high pulse-rate laser ablation. Appl. Phys. A, Mater. Sci. and Proc, 1999; 69: S755-S758. 
7. Bongiorno G, Podestá A, Ravagnan L, Piseri P, Milani P, Lenardi C, et al. Electronic properties and applications of cluster-assembled carbon films. J. Mater. Sci. Mater. Electron., 2006; 17(6): 427-441.

8. Rode AV, Elliman RG, Gamaly EG, Veinger AI, Christy AG, Hyde ST, et al. Electronic and magnetic properties of carbon nanofoam produced by high-repetition-rate laser ablation. Appl. Surf. Sci., 2002; 197: 644-649.

9. Bruzzi M, Piseri P, Miglio S, Bongiorno G, Barborini E, Ducati C, et al. Electrical conduction in nanostructured carbon and carbon-metal films grown by supersonic cluster beam deposition. Eur. Phys. J. B, 2003; 36(1): 3-13.

10. Shiozawa H, Giusca CE, Silva SRP, Kataura H, Pichler T. Capillary filling of singlewalled carbon nanotubes with ferrocene in an organic solvent. Phys. Stat. Sol. B, 2008; 245(10): 1983-1985.

11. Rümmeli MH, Borowiak-Palen E, Gemming T, Pichler T, Knupfer M, Kalbak M, et al. Novel catalysts, room temperature, and the importance of oxygen for the synthesis of single-walled carbon nanotubes. Nano Lett., 2005; 5(7): 1209-1215.

12. lijima S. Helical Microtubules of Graphitic Carbon. Nature, 1991; 354(6348): 56-58.

13. Dijkkamp D, Venkatesan T, Wu XD, Shaheen SD, Jisrawi N, Min-Lee NH, et al. Preparation of $\mathrm{Y}-\mathrm{Ba}-\mathrm{Cu}$ oxide superconductor thin films using pulsed laser evaporation from high $\mathrm{T}_{\mathrm{C}}$ bulk material. Appl. Phys. Lett., 1987; 51(8): 619-621.

14. Miyajima Y, Shannon JM, Henley SJ, Stolojan V, Cox DC, Silva SRP. Electrical conduction mechanism in laser deposited amorphous carbon. Thin Solid Films, 2007; 516(2-4): 257-261.

15. Ashfold MNR, Claeyssens F, Fuge GM, Henley SJ. Pulsed laser ablation and deposition of thin films. Chem. Soc. Rev., 2004; 33(1): 23-31.

16. Lowndes DH, Geohegan DB, Puretzky AA, Norton DP, Rouleau CM. Synthesis of novel thin-film materials by pulsed laser deposition. Science, 1996; 273(5277): 898-903.

17. Droubay, T.C., Qiao L, Kaspar TC, Engelhard MH, Shutthanandan V, Chambers SA. Nonstoichiometric material transfer in the pulsed laser deposition of $\mathrm{LaAlO}_{3}$. Appl. Phys. Lett., 2010; 97(12): 124105-3.

18. Henley SJ, Carey JD, Silva SRP, Fuge GM, Ashfold MNR, Anglos D. Dynamics of confined plumes during short and ultrashort pulsed laser ablation of graphite. Phys. Rev. B, 2005; 72(20): 205413.

19. Henley SJ, Carey JD, Silva SRP. Room temperature photoluminescence from nanostructured amorphous carbon. Appl. Phys. Lett., 2004; 85(25): 6236-6238.

20. Sullivan JP, Friedmann TA, Baca AG. Stress relaxation and thermal evolution of film properties in amorphous carbon. J. Electron. Mater., 1997; 26(9): 1021-1029.

21. Ferrari AC, Robertson J. Interpretation of Raman spectra of disordered and amorphous carbon. Phys. Rev. B, 2000; 61: 14095.

22. Ferrari AC, Robertson J. Raman spectroscopy of amorphous, nanostructured, diamond-like carbon, and nanodiamond. Philos. T. Roy. Soc. A, 2004; 362(1824): 2477-2512.

23. Amaratunga GAJ. Robertson J, Veerasamy VS, Milne WI, Mckenzie DR. Gap States, Doping and Bonding in Tetrahedral Amorphous-Carbon. Diam. Relat Mater., 1995; 4(56): 637-640.

24. Ferrari AC, Kleinsorge B, Morrison NA, Hart A, Stolojan V, Robertson J. Stress reduction and bond stability during thermal annealing of tetrahedral amorphous carbon. J. Appl. Phys., 1999; 85(10): 7191-7197. 
25. Miyajima Y, Adikaari AADT, Henley SJ, Shannon JM, Silva SRP. Electrical properties of pulsed UV laser irradiated amorphous carbon. Appl. Phys. Lett., 2008; 92(15): 152104.

26. Khan RU. Conduction and doping of a-C. In: Silva SRP, Editor. Properties of amorphous carbon. London; INSPEC; 2003, p 209-216.

\section{Figure captions}

Fig. 1. Plan view SEM micrographs of thin films formed by $248 \mathrm{~nm}$ PLA of the C:Ni target at $p(\mathrm{Ar})=$ (a) 5 mTorr, (b) 40 mTorr, (c) 100 mTorr and (d) 340 mTorr. The inset in panel (d), where the scale bar is $2 ? \mathrm{~m}$, shows the foam-like structure of the film deposited at the edge of the substrate under $p(\mathrm{Ar})=340$ mTorr. Panels (e) and (f) are expanded micrographs of films deposited at $p(\mathrm{Ar})=$ at $340 \mathrm{mTorr}$, before and after annealing at $573 \mathrm{~K}$ respectively. No clear structural change is evident upon annealing. 
Fig. 2. $514.5 \mathrm{~nm}$ Raman spectra of the (a) as-deposited and (b) annealed films grown at several different values of $p(\mathrm{Ar})$ by $248 \mathrm{~nm}$ PLA of the pyrolytic graphite target; (c) and (d) are corresponding spectra of the as-deposited and annealed films, respectively, that were grown from the mixed C:Ni target, again by $248 \mathrm{~nm}$ PLA at various $p(\mathrm{Ar})$. The values of $p(\mathrm{Ar})$ under which these films were produced were (i) 5, (ii) 40, (iii) 100 and (iv) 340 mTorr.

Fig. 3. $I(\mathrm{D}) / I(\mathrm{G})$ ratios from the Raman spectra of the as-deposited (filled symbols) and annealed (open symbols) films grown at different $p$ (Ar) by $248 \mathrm{~nm}$ PLA of (a) the pyrolytic graphite target and (b) the mixed C:Ni target. The G-peak wavenumbers are indicated in panel (c) for the films deposited using the pyrolytic graphite target and in panel (d) for the C:Ni target. The dashed lines are intended to reflect the approximate trend with pressure for the as-deposited and annealed films, respectively.

Fig. 4. $I-V$ characteristics of films grown by $248 \mathrm{~nm}$ PLA of the pyrolytic graphite and the mixed C:Ni target at $p(\mathrm{Ar})=$ (a) 5, (b) 40, (c) 100 and (d) 340 mTorr. The label $\mathrm{C}$ indicates curves for films deposited using the pyrolytic graphite target, while curves labelled with $\mathrm{C}: \mathrm{Ni}$ are those for the films deposited using the mixed target.

Fig. 5. Spatial variation of the nickel content (in at. \%) for the film deposited by $248 \mathrm{~nm}$ PLA of the $\mathrm{C}: \mathrm{Ni}$ target in $p(\mathrm{Ar})=340 \mathrm{mTorr}$.

Fig. 6. SEM images of thin films deposited following $193 \mathrm{~nm}$ PLA of the $\mathrm{C}: \mathrm{Ni}$ target at $p(\mathrm{Ar})=$ (a) $10^{-3}$ mTorr, (b) 40 mTorr, (c) 100 mTorr and (d) 340 mTorr. The C:Ni ratios inset in each image indicate the atomic percentage of the two elements as obtained through EDX analysis.

\section{Table captions}

Table 1. C and Ni content (in at. \%) as determined by EDX spectroscopy for the target and for films deposited by PLA of the mixed C:Ni target at different $p(\mathrm{Ar})$. 